\title{
Perception analysis of highway quality of service using a driving simulator and eye tracking system
}

\author{
Cintia Isabel de Campos ${ }^{1}$, Leandro Arab Marcomini ${ }^{2}$, Natália Ribeiro Panice ${ }^{3}$, \\ Fernando José Piva ${ }^{4}$, Ana Paula C. Larocca ${ }^{5}$
}

\author{
1University of São Paulo, São Paulo, Brazil, cintiaidecampos@gmail.com \\ ${ }^{2}$ University of São Paulo, São Paulo, Brazil, leandro.moh@gmail.com \\ 3University of São Paulo, São Paulo, Brazil, panice.natalia@gmail.com \\ 4University of São Paulo, São Paulo, Brazil, fjpiva@usp.br \\ ${ }^{5}$ University of São Paulo, São Paulo, Brazil, larocca.ana@usp.br
}

\section{Recebido:}

17 de abril de 2019

Aceito para publicação:

15 de abril de 2020

Publicado:

31 de agosto de 2020

Editor de área:

Sara Ferreira

\section{Keywords:}

Driving simulator.

Highway.

Quality of service.

User's perception.

\section{Palavras-chaves:}

Simulador de direção.

Rodovia.

Qualidade de serviço.

Percepção do usuário.

DOI:10.14295/transportes.v28i3.2015

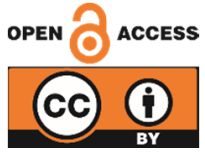

\begin{abstract}
In this study, we investigated drivers' behavior in a highway considering their perception of the quality of service as a function of surrounding traffic conditions, using a driving simulator and an eye tracking system. The driving simulator allows to create different driving environments very similar to real-life driving scenarios. We developed three different scenarios, with traffic densities based on different levels of service, and also prepared a questionnaire to evaluate user perception. Data from the questionnaire, the driving simulator, and the eye tracking system for twenty participants were included in our database. We performed statistical analysis using nonparametric tests (KruskalWallis and Tukey tests) and measured Pearson's correlation coefficients between variables. Within this preliminary approach, drivers were able to differentiate between the scenarios and were able to determine scores for each level of service presented. These results suggest that driving simulators have considerable potential for the evaluation of quality of service (QoS) perception.
\end{abstract}

\section{RESUMO}

Neste estudo, investigamos o comportamento do motorista em uma rodovia considerando a percepção sobre a qualidade de serviço em função das condições de tráfego, usando um simulador de direção e um sistema de rastreamento ocular. O simulador de direção permite criar ambientes de direção diferentes, muito semelhantes aos cenários de direção da vida real. Desenvolvemos três cenários diferentes, com densidades de tráfego baseadas em diferentes níveis de serviço, e também preparamos um questionário para avaliar a percepção do usuário. Os dados do questionário, do simulador de direção e do sistema de rastreamento ocular de vinte participantes foram incluídos em nosso banco de dados. Realizamos análise estatística usando testes não paramétricos (testes de Kruskal-Wallis e Tukey) e medimos os coeficientes de correlação de Pearson entre as variáveis. Nessa abordagem preliminar, os motoristas conseguiram diferenciar os cenários e determinar as pontuações para cada nível de serviço apresentado. Esses resultados sugerem que os simuladores de direção têm um potencial considerável para a avaliação da percepção da qualidade de serviço (QoS).

\section{INTRODUCTION AND BACKGROUND}

Installation of any mode of transport is a service provided to society. Therefore, it is essential that its quality can be measured for assessment by traffic engineers, transport planners and public policy makers. Around the world and especially in upcoming countries, there is growing consensus that the design, update and even maintenance of a transport facility must be largely based on demand. Proper consideration of this demand needs to examine aspects such as end users' perceptions and aspirations for the installation. 
The Level of Service (LOS) of a highway can be evaluated through parameters such as traffic density, speed, road infrastructure (lanes and shoulders), maneuverability, and user perception regarding quality of service (TRB, 2010).

Traffic density is considered the most representative measure for user perception in terms of evaluating the quality of service. The reason for that is, when approaching capacity, the flow becomes more discernible to the user. Moreover, there is the impact that operating speed has, wherein the average speed is constant until LOS C (TRB, 2010), but starts to suffer impacts as the density rises on the other levels.

User perception, which is one of the ways to assess LOS, consists in to exhibit real or simulated videos on a screen, with different traffic density conditions, and apply a questionnaire for evaluation (Fang et al., 2003; Choocharukul et al., 2004; Washburn and Kirschner, 2006; Fang and Pecheux, 2009; Oliveira, 2009; Obelheiro et al., 2011; Paiva and Setti, 2015; Jensen, 2017). The advantage of using real-world videos is that they show real-world traffic, with realworld proportions and feel. However, the production of these videos requires more resources, such as different cameras for different views (front, rear, and speedometer) and appropriate combination and synchronization of the footages acquired in this way. Therefore, studies using real-world videos tend to show a more limited range of operating conditions. The use of videos of simulated traffic permits complete control of all factors that may affect the traffic stream. On top of that, it requires very few resources to record.

The main disadvantage of using simulated traffic videos limited fidelity of the simulation. The graphics need to be as realistic as possible and the behavior of vehicles needs to be as close as possible to the real world. Simulation fidelity can be improved via calibration of simulation parameters (Dowling, Skabardonis and Alexiadis, 2004; Paiva and Setti, 2015; Bethonico et al., 2016). However, researchers cannot control image and graphics quality because these options are determined by the software capabilities.

An alternative to assess user perception is the use of driving simulators. Their main advantage compared to video displays is that the equipment, which is similar to real car controls, allows the participant to feel as in the traffic without any risks, while experiencing simulated scenarios. The number of research simulators continues to increase worldwide, and simulator studies represent an increasing proportion of the research literature on driving performance and behavior.

According to FHWA (2014), many driving behaviors can be studied with success in low and medium fidelity driving simulators, especially when the drivers' cognitive behavior and the decision making process are the objects of investigation. There are several researches using driving simulators in different fields, such as engineering, medicine, and psychology, that investigate traffic signs usage, geometric design of roads, drug use effects, cellphone use effects, night-driving, driver's fatigue and stress levels (Fisher et al., 2011; Katsikopoulos, 2011; Ramaekers, 2011; Strayer et al., 2011; Wood and Chaparro, 2011; Matthews et al, 2011). This demonstrates the importance and versatility of a driving simulator to the development of studies with different objectives.

\subsection{Level of Service (LOS)}

LOS can be based on traffic stream density, which is the main performance measure for it. Table 1 shows the LOS characteristics, from A to F, according to the HCM (TRB, 2010). 
Table 1 - LOS characteristics

\begin{tabular}{llllll}
\hline \multicolumn{2}{l}{ LOS Average speed } & $\begin{array}{l}\text { Average spacing } \\
\text { between vehicles }\end{array}$ & $\begin{array}{l}\text { Freedom to } \\
\text { Maneuver }\end{array}$ & $\begin{array}{l}\text { Psychological } \\
\text { comfort }\end{array}$ & Incidents \\
\hline A & Free flow & More than 160m & Complete & Excellent & Irrelevant \\
\hline B & Free flow & About 100m & Easier & High & No impacts on the flow \\
\hline C & $\begin{array}{l}\text { Equal to or very close to } \\
\text { the free flow speed }\end{array}$ & Between 67 and 100m & Less easy & Considerable drop & Few impacts, without traffic jams \\
\hline D & Less than free flow speed & Between 50 and 67m & Limited & Uncomfortable & Creates traffic queues \\
\hline E & Less than free flow speed & Between 37 and 50m & Almost none & Very low & Creates traffic jam \\
\hline F & Unstable flow & Heavy traffic jam & Traffic queues & & \\
\hline
\end{tabular}

The standard measure of vehicular density used to estimate the LOS in highways is passenger car equivalent (PCE). Furthermore, there are two other factors: space average speed, and the ratio between demand and capacity $(\mathrm{v} / \mathrm{c})$.

\subsection{User's perception}

When working with transportation systems, the quality of service perception is determined by the experience that the user has in different situations and the way in which information is processed (Paiva, 2015). Though there are many factors that influence the driver's perception, there is not enough knowledge regarding the most adequate ones to represent the quality of service perceived by the driver (Washburn et al., 2004).

In rural highway studies, the rate of traffic flow had the greatest association with the level of driver's satisfaction. Other variables were also considered: quantity of lane changes, time spent following a slower car, driving experience and frequency, desired speed, speeding, freedom to maneuver, road condition, driver's civility, and the presence of road construction or maintenance works (Nakamura et al., 2000; Washburn et al., 2004).

According to Choocharukul et al. (2004) and Papadimitriou et al. (2010), the quality of service perception in urban highway settings is influenced by different variables: density, number of lanes, average speed, speed variation, headway variation, heavy vehicles percentage, demographic variables, driver's experience, driver's familiarity with the highway, vehicle's engine, and traffic flow.

In a study by Hall et al. (2001), the total trip time was the most important factor in quality perception for frequent drivers, with regard to the level of service and the driver's type. When Hostovsky and Hall (2003) analyzed professional truck drivers, the most important factors were total trip time (speed), traffic density (maneuverability), and traffic flow. According to Hostovsky et al. (2004)'s study, trip time was a determinant for urban area trips and freedom to maneuver was a characteristic for rural area trips. In the same study, experienced drivers worried more about traffic flow and road conditions. Characteristics from highways, traffic, rural highway trips, user, and density, all contribute to the quality of service prediction modeling, but traffic density is the most prominent.

\subsection{User's perception identification}

According to the Highway Capacity Manual - HCM - (TRB, 2010), ways to collect information about the quality of service can be determined, and must contain:

- Observation of perceivable and important factors to the driver (directly or indirectly);

- Driver's complaints and praises; 
- Satisfaction prediction by use of previous researches and models;

- Observation of non-perceived facts by the drivers that affect perceived measurements.

A few methods were proposed to obtain information about the user's perception: focal groups, questionnaires, and recording field experiments driving cars (TRB, 2010). Although simulators may also be considered an adequate method, the HCM does not recognize it. Moreover, it is believed that a few of the difficulties listed by the HCM can be surpassed with the use of microscopic traffic simulators and driving simulators (Paiva, 2015).

Among those difficulties, the HCM lists: i) limitations in conceiving a method that embraces all factors perceived by the driver at the same time that removes all the irrelevant factors that may divert the focus of the research; ii) replicating those conditions. Given that those difficulties are related to field studies, where you have almost no control of local conditions, driving simulators can be the solution.

Even though the perception of field studies is more complete, simulation allows one to filter undesirable factors and to adequate to a certain amount of factors to be studied (Paiva, 2015; Vieira et al., 2017). Besides, between other advantages the simulator has, there is the possibility to recreate as many times as necessary the same scenarios and situations from real life. With this control, it is possible to monitor driving performance and to identify variables that affect this same performance, even in risk situations, which would be impossible otherwise (FHWA, 2014).

\subsection{Driving simulators}

The ease with which the elements (traffic, weather conditions, road layout) of a virtual environment can be manipulated and tailored to meet specific research requirements (de Winter et al., 2012), the accuracy and efficiency of data collection and the safe environment devoid of the risks associated with real-life driving scenarios,accounts for the increased use of driving simulators in research (Rizzo et al., 2002).

A driving simulator can be defined by the driver's interaction with a simulated environment, using equipment that reproduces usual car controls. All the interactions and the environment are continuously monitored. They can be categorized according to use (training or research) and cost (low, medium, high). The equipment represents the direct interface between the simulator and the driver; the equipment is usually composed of the steering wheel, pedals, gear stick, screens, and sound equipment. Different pieces of software are responsible for processing inputs, generating results displayed to the driver, and for the storage of all data. The combination of equipment and software allows us to classify driving simulators on another basis: realism, or fidelity. Low-fidelity simulators have limited equipment to simulate the world and to accept user inputs. High-fidelity simulators have the ability to simulate all aspects of driving a car and the world around the driver. The higher the level of fidelity, the higher the costs to implement it (Santos et al., 2017).

Different studies validated the use of driving simulators to evaluate issues related to traffic systems. Simulators were effective in applications regarding driving behavior, road safety, driving under the influence of drugs and alcohol, sleep-deprived driving, the effect of mental disorders on driving and hazard perception (Blana, 1996; Chan et al., 2010; Underwood et al., 2011; Knapper et al., 2015). 
Studies of user perception of the quality of service of highways use mainly the video exhibition method. Compared to this approach, the driving simulator is more advantageous because it allows the driver to interact with the traffic flow through the equipment, simulating a real driving task without putting the participant's life at risk. However, there are no studies using a driving simulator to assess the quality of the service from the perspective of the user.

The objective of this experiment was to evaluate the user perception of the highway quality of service in a medium-fidelity driving simulator under different traffic density conditions. To this aim, we used a virtual environment of a real highway section from Brazil, with different LOS represented by three different simulated densities. The driver's behavior was analyzed by considering the correlation between driving simulator, eye tracking system and questionnaire data using Pearson's correlations and ANOVA.

In addition to the introduction and background, this paper presents three more sections. In Section 2, we describe the materials and method, providing information about the simulator, the simulated scenarios and the adopted procedure. The results are presented and discussed in Section 3. Finally, Section 4 presents our final considerations, including limitations of the method and recommendations for future work.

\section{MATERIALS AND METHOD}

The research development consisted of four main steps: development of a questionnaire, scenario creation and testing, data collection, and analysis of results. The study has a nonprobabilistic sampling composed of university students, chosen by convenience. Voluntary participation of drivers to the study was invited through an announcement within the University Campus. We excluded students and staff from the Transportation Engineering Department to avoid any bias related to previous knowledge of the driving simulator characteristics.

\subsection{Relationship between driver behavior and LOS}

The LOS along highway is a function of traffic volume, average speed of the traffic stream, travel time as well as the extent to which drivers can maneuver between vehicles. Three scenarios of various traffic volumes were designed to match traffic speed of LOS A, C and E. The driving simulator software recorded participant's speed, acceleration, brake, and so on for about every 60 second as they drive through the corridor.

\subsection{Questionnaire}

We developed a questionnaire with three different parts according to the study goals. The first part was a characterization of the participant, considering sociodemographic and driver experience data. We asked about age, level of education, type of driver's license, highway driving frequency, and kilometers driven per month.

The second part had questions that assessed the quality of service of each scenario, under two aspects: i) driving: level of easiness perceived during the driving period related to the easiness to maintain speed or to change lanes; ii) road environment: quality of service regarding traffic conditions (vehicles density) and psychological comfort of the driver.

The driving easiness questions were "How easiness was for you to change lanes?" and "What was the easiness in maintaining the desired speed?", both ranked on a four-point scale, 
where 1 is the hardest situation for driving, and 4 is the easiest. Participants were instructed to consider traffic characteristics to answer.

In the quality of service questions, the participants answered "How do you consider highway's quality of service while driving?" considering two different factors: i. traffic conditions related to the number of vehicles and speed) and ii. psychological comfort (stress, nervousness, annoyance due to traffic) on a scale from zero to ten, where zero represented the worst quality and ten, the best quality.

The third part aimed to identify aspects that had more influence in the grades attributed to the three scenarios. The participants made a unique ranked for the number of vehicles, the easiness to maintain the desired speed, and the easiness to change lanes from the most important to the less important.

\subsection{Driving simulator characteristics}

The driving simulator used in this study is a medium-fidelity simulator, with a fixed-base seat and projection screen to simulate the environment, installed in an adapted room, with air-conditioning, black walls, ceiling, and floor. The scenario is projected on a central screen with a DepthQ® HDs3D2 1080p and $60 \mathrm{~Hz}$ projector. Two speakers reproduce ambiance and vehicle sounds. The eye-tracking device uses a Smart Eye Pro 5.10 system, built with three frontal cameras for increased precision. The system collected the gaze direction and position in real time.

\subsection{Simulated scenarios}

The virtual scenario simulated the south segment of Régis Bittencourt (BR-116), a rural and sinuous Brazilian highway, between the kilometers 509+000 and 518+400. It has three lanes in each direction, with an average grade of $4.8 \%$. The comparison between the real world highway and the simulated scenario is in Figure 1.

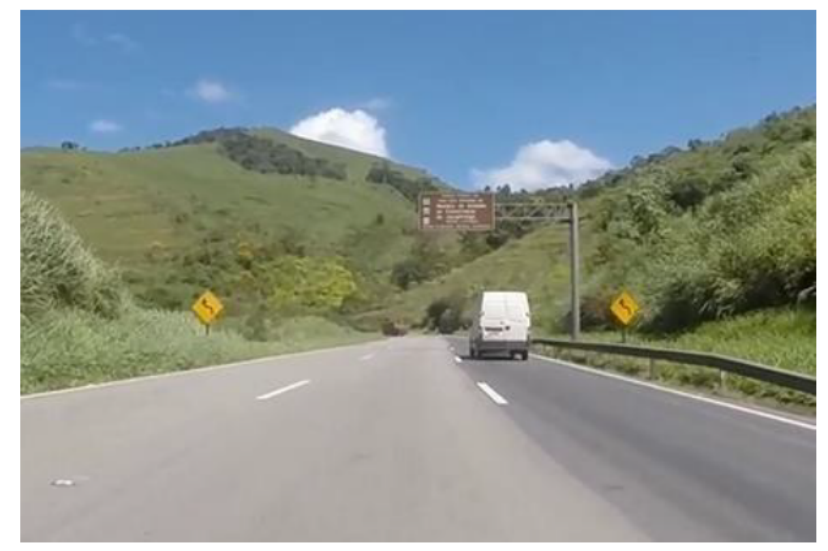

(a)

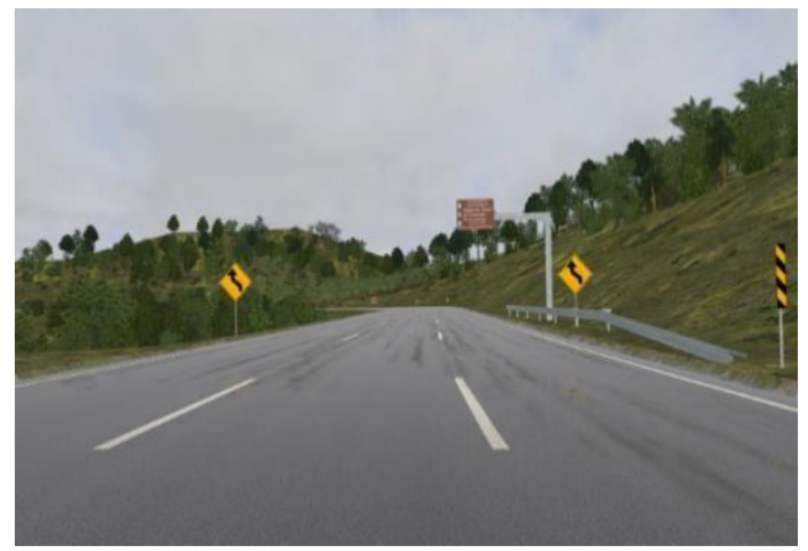

(b)

Figure 1. Highway and scenario (a) real world highway (b) virtual scenario. Source: Santos et al. (2017)

The simulated scenario was built in the software Virtual Test Drive (VTD), by Vires. The tools available in the software enable the creation of roads, scenarios, vehicle traffic, sounds and images in real time. For all vehicle models, the software VI-CarRealTime $\AA$ was used, which allows for the tuning of specific physics parameters. 
We developed three different configurations for the same segment, each with different traffic densities, as per the levels of service established by the HCM (TRB, 2010). We focused on the upper limits of the levels "A", "C", and "E", to emphasize differences among different scenarios. Moreover, the inclusion of all levels of service (A to E) could have caused excessive driver's tiredness due to driving for too long. Figure 2 shows the virtual scenarios included in the experiment.
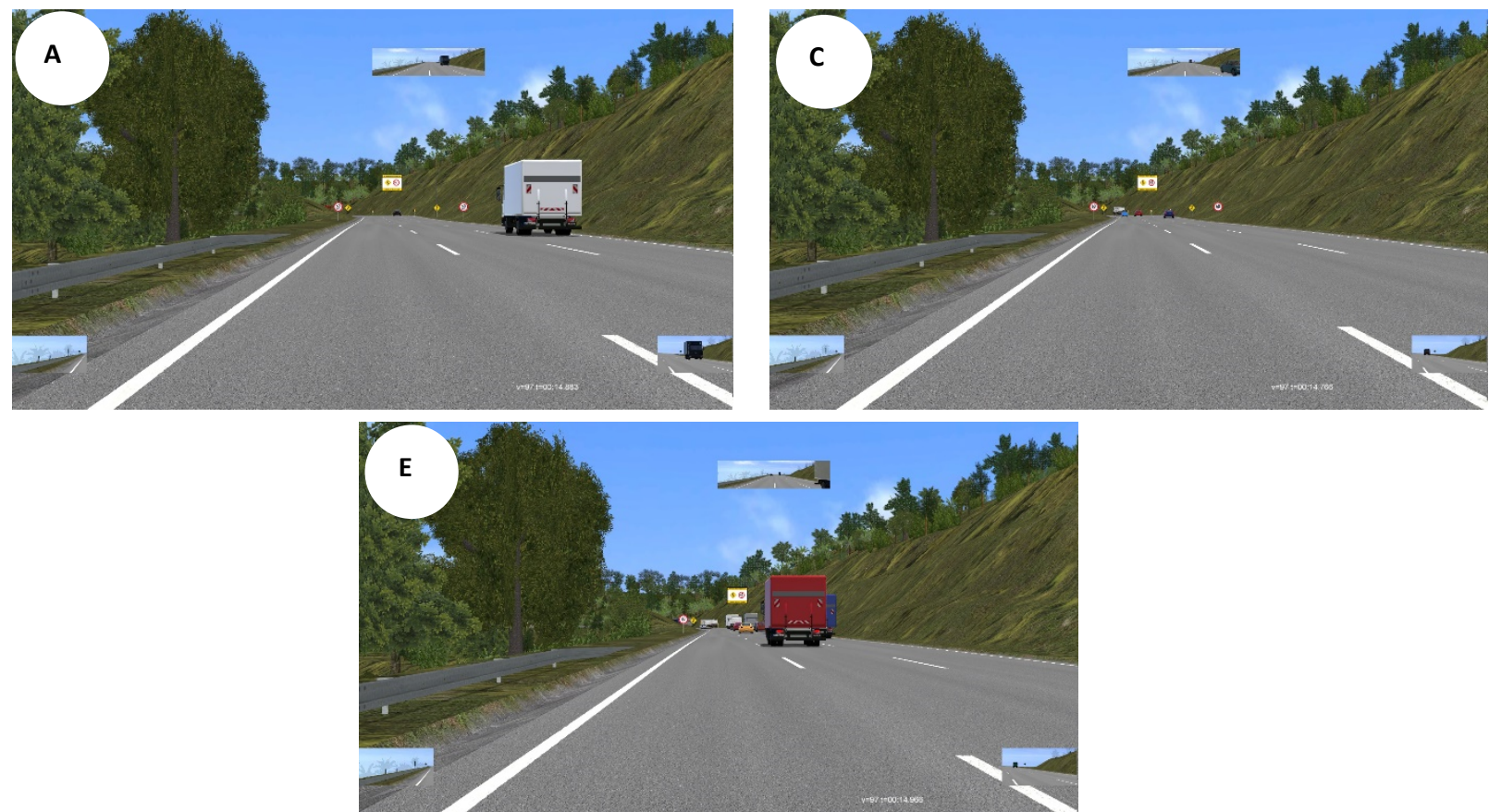

Figure 2. Simulated scenarios images - levels " $A$ ", " $C$ ", and " $E$ "

We calculated the traffic composition according to data collected in tollbooths near the studied segment, which presented approximately $60 \%$ of heavy vehicles and $40 \%$ of light vehicles. A total of 12 spots, 10 curves and 2 tangents were marked as important locations for collecting operating speed data and calculating the operating speed ( $\left.\mathrm{V}_{85}\right)$. These spots were free of speed trap, local access, and other interferences that could affect the results. For data collection, the auto-operated electronic traffic monitoring system MetroCount $($ (MC-5600) was used. Although the local legal speed limit is $60 \mathrm{~km} / \mathrm{h}$, the operating speed $\left(\mathrm{V}_{85}\right)$ in the segment was $85 \mathrm{~km} / \mathrm{h}$ for light vehicles and $70 \mathrm{~km} / \mathrm{h}$ for heavy vehicles (Torres, 2016; Larocca et al., 2018). Thus, we adopted the operating speed to replicate the local reality.

We used an equivalency factor of 3 pce for heavy vehicles, as obtained from HCM (TRB, 2010), on roads with $25 \%$ or more heavy vehicles and grade between $4 \%$ and $5 \%$. We calculated, based on the density of each level of service, the number of vehicles around the driver in a given moment. The considered parameters are in Table 2.

Table 2 - Densities and vehicles quantities in each scenario

\begin{tabular}{lllll}
\hline LOS & $\begin{array}{l}\text { Density per lane } \\
\text { (pce/(km.ln)) }\end{array}$ & $\begin{array}{l}\text { Traffic density } \\
\text { (veh//km) }\end{array}$ & $\begin{array}{l}\text { Heavy Vehicles } \\
\text { (veh//km) }\end{array}$ & $\begin{array}{l}\text { Light Vehicles } \\
\text { (veh//km) }\end{array}$ \\
\hline A & 6.8 & 9.3 & 6 & 4 \\
C & 16.2 & 22.1 & 13 & 9 \\
E & 28.0 & 38.2 & 23 & 15 \\
\hline
\end{tabular}


We configured two radii around the driver: a smaller one, to define the minimum distance from the driver to generate a simulated vehicle; a larger one, to define the maximum distance that a simulated vehicle can appear. The smaller radius has the purpose to avoid the appearance of vehicles in the driver's field of view, while the bigger radius limits the rendering area for the simulator, decreasing the processor load. In all scenarios, the smaller radius has 200 meters and the bigger one, 400 meters.

\subsection{Research trials}

The study, rules were explained to the participants and practice sessions were initiated to familiarize participants with the simulator and simulated environment.

All trials occurred in the period of a week. All participants drove on the same highway segment, each time with a different traffic density, simulating the superior limits of each LOS studied, "A", "C" and "E". We presented the scenarios in the order " $A$ ", " $E$ " and " $C$ " for all participants.

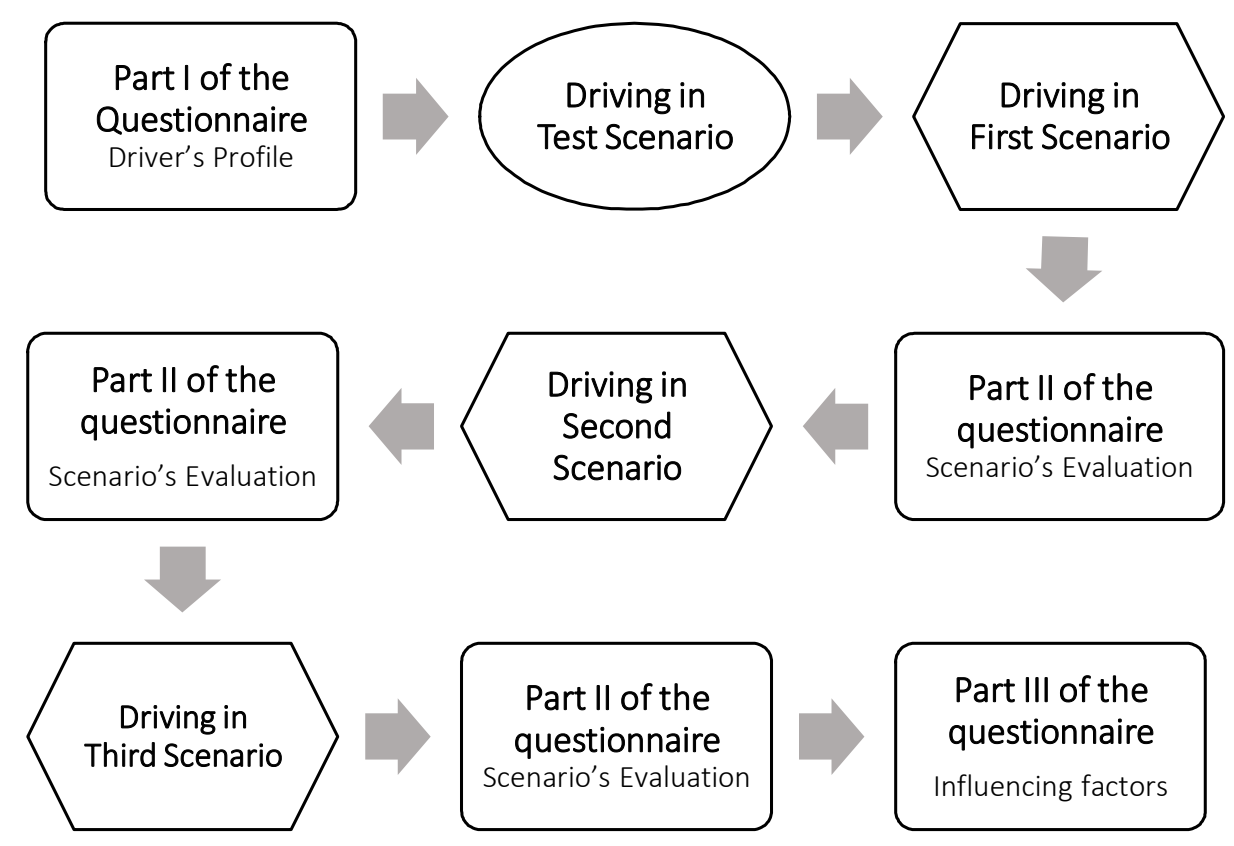

Figure 3. Experiment flowchart

Drivers answered the first part of the questionnaire before driving on the scenarios. Before the beginning of the actual trial, they drove on a scenario with no traffic flow, to get used to the simulator. After this adaptive time, we started the experiments with three different scenarios. After each scenario, we apply part of the questionnaire to evaluate the driver's perception regarding the presented scenario. At this stage, we read the questions so the driver did not need to leave the simulator during the trials. The participant answered the third and last part of the questionnaire after driving all scenarios. The sequence of the experiment is in Figure 3.

\subsection{Statistical analysis}

We performed all statistical tests using the software IBM® SPSS $®$ Statistics 22.0. The analysis of variance (ANOVA) is a technique used at the beginning of a statistical analysis to determine 
if samples from two or more groups are part of populations with the same averages, in the search for significant statistical results. It evaluates differences in a single metric dependent variable (Oehlert, 2010; Hair, Jr. et al., 2005).

The Kruskal-Wallis test is a non-parametric method that shows if two independent groups are different. A comparison is made for cases with one variable (Field, 2009). If the significance of the test is lower than $\alpha=0.05$, then the null hypothesis must be rejected in favor of the alternative hypothesis. Because the test does not indicate between which one of the groups there is a difference in the probability distribution, one alternative is to complement the result with the Tukey test (Arditi et al., 2007).

The post hoc Tukey test analyses average differences between all possible combinations of groups, with strict confidence intervals. From this method, it is possible to identify which combination has a significant difference, making the process of interpretation easier. When the objective is the comparison of averages, this test is an excellent exploratory tool (Hair, Jr. et al., 2005; Montgomery, 2013).

Both, ANOVA and the Tukey test are widely used in studies with driving simulators (Horberry et al., 2006; Van Driel et al., 2006; Antonson et al., 2007; Schultheis et al., 2007; Figueira et al., 2020). For the comparison between groups, it is also common to use the Kruskal-Wallis test (Arditi et al., 2007; Sullman and Baas, 2003).

\section{RESULTS}

The tests in the driving simulator relied on a sample of twente drivers with an average age of 26.2 years old $(S D=4.274 ; \min =21 ; \max =38), 55 \%$ men and $45 \%$ women. As for the education level, $80 \%$ of them had a college degree and $20 \%$ had an undergraduate education. The majority of drivers (70\%) had a driver's license type B (that allows them to drive a vehicle with maximum weight of 3.5 ton and maximum capacity of nine seats) and 5.65 ( $\mathrm{SD}=3.453$, $\min =1$; $\max =$

13) years of driver license, on average. The total travel distance for most participants (58\%) was between 101 and $500 \mathrm{~km}$ (58\%), while the travel frequency on highways was monthly for $42 \%$ of the drivers, weekly for $32 \%$, daily for $11 \%$, and rare for the remaining drivers.

\subsection{Descriptive analysis from questionnaire variables}

The questionnaire variables considered in the analysis were easiness to change lanes, easiness to maintain speed, traffic conditions, and psychological comfort. The highest and lowest average scores for easiness to change lanes and to maintain speed were observed in scenario " $\mathrm{A}$ " and "E", respectively (Table 3). This may be associated with increased traffic density, which creates more difficulties to maneuver and to maintain the speed the driver deemed appropriate.

Table 3 indicates that for traffic conditions and psychological comfort, the highest average grade was assigned to scenario " $A$ " and the lowest average grade to scenario " $E$ ". This fact may indicate that the driver considered the quality of service to be improved at lower density, in agreement with the literature. In other words, the number of vehicles and the speed of other drivers did not prevent the movements that he wanted to do in the lowest density scenario. 
Table 3 - Descriptive measures of variables in Part II of the questionnaire

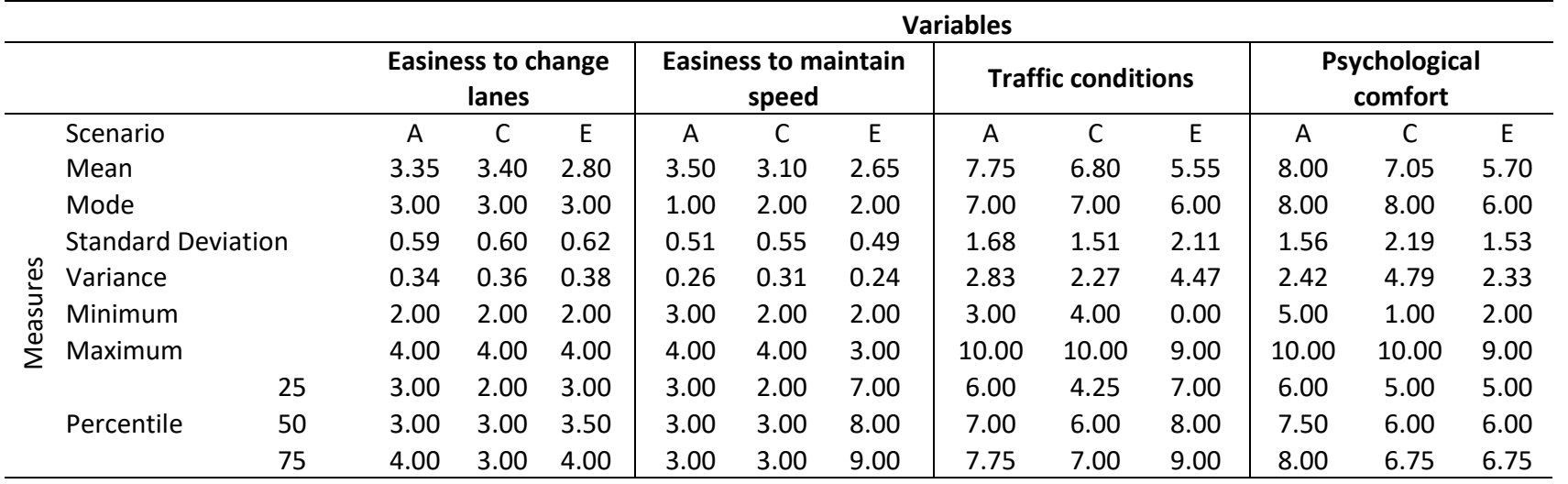

\subsection{Descriptive analysis from simulator variables}

Among the variables obtained from the records of the driving simulator and from eye tracking devices, the factors included in the analysis were average speed, time spent to look at the rearview mirrors, time spent to look at the speedometer and quantity of lane changes. The corresponding descriptive measures are presented in Table 4.

As for the average speed performed by drivers, scenario " $\mathrm{C}$ " yielded the highest average values. This may be related with increased familiarity with the simulator, since scenario "C" was the last one presented to the participant. Scenario "E" obtained the lowest values of speed and drivers looked more to the mirrors, which may indicate a degree of discomfort for the driver, due to the presence of more vehicles.

Table 4 - Descriptive measures of the simulator and eye tracking variables

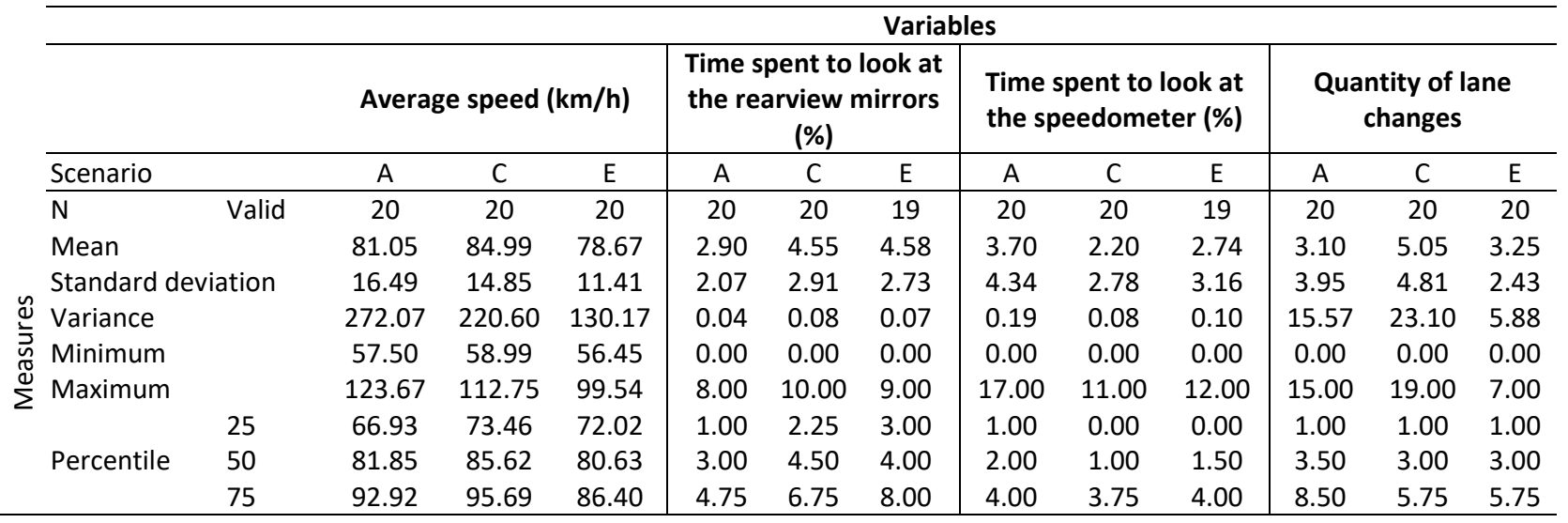

No clear trend was revealed upon analysis of the average values for eye fixation time on the speedometer and number of lane changes. Scenario "E", characterized by the highest traffic density, displayed at least one lane change, i.e., the highest drivers' activity. In scenario " $C$ ", the time spent to look at the rearview mirrors was higher than in scenario " $\mathrm{A}$ ", indicating that the drivers paid more attention and care.

\subsection{Variables correlation}

We analyzed Pearson's correlations between the questionnaire variables (easiness to change lanes, easiness to maintain speed, traffic conditions, and psychological comfort), simulator 
variables (average speed, time spent to look at the rearview mirrors, time spent to look at the speedometer and quantity of lane change), and driver's experience characteristics.

It is worth noting that most correlations are statistically significant at a confidence level of $99 \%$, as shown in Table 5. The correlation between psychological comfort and traffic conditions (0.630) was the highest one, with good grades for traffic condition followed by good grades for psychological comfort.

The variable easiness to change lanes showed a direct correlation with the variables easiness to maintain speed (0.425), psychological comfort (0.391) and traffic conditions (0.386). As the correlations between variables were direct, drivers who attributed a low grade for the easiness to change lanes also attributed a low grade for the easiness to maintain speed, in addition to relating unfavorable traffic conditions to the greater number of vehicles and speed of other drivers. It is also evident that the driver had a psychological discomfort due to stress and traffic.

The results indicated a direct correlation between easiness to maintain speed and traffic conditions (0.547) and between easiness to maintain speed and psychological comfort (0.473). Likewise, drivers who evaluated with low scores the easiness to maintain speed also gave low scores to traffic conditions and psychological comfort experienced while driving.

Table 5 - Questionnaire and simulator variables correlation matrix

\begin{tabular}{|c|c|c|c|c|c|}
\hline & & $\begin{array}{l}\text { Easiness to } \\
\text { change lanes }\end{array}$ & $\begin{array}{c}\text { Easiness to maintain } \\
\text { speed }\end{array}$ & $\begin{array}{c}\text { Traffic } \\
\text { conditions }\end{array}$ & $\begin{array}{c}\text { Average } \\
\text { speed }\end{array}$ \\
\hline \multirow[t]{2}{*}{ Easiness to maintain speed } & Pearson & $0.425^{* *}$ & & & \\
\hline & Sig & 0.001 & & & \\
\hline \multirow[t]{2}{*}{ Traffic conditions } & Pearson & $0.386 * *$ & $0.547 * *$ & & \\
\hline & Sig & 0.002 & 0.000 & & \\
\hline \multirow[t]{2}{*}{ Psychological comfort } & Pearson & $0.391 * *$ & $0.473 * *$ & $0.630 * *$ & \\
\hline & Sig & 0.002 & 0.000 & 0.000 & \\
\hline \multirow[t]{2}{*}{ Time spent to look at the speedometer (\%) } & Pearson & & & & $-0.302 *$ \\
\hline & Sig & & & & 0.020 \\
\hline \multirow[t]{2}{*}{ Quantity of change lane } & Pearson & & & & $0.423 * *$ \\
\hline & Sig & & & & 0.001 \\
\hline
\end{tabular}

The average speed was inversely correlated with the time spent to look at the speedometer $(-0.302)$ and directly correlated to the number of lane changes $(0.423)$. In this case, the longer the driver looked at the speedometer, the lower the speed he gave to the vehicle. This may have happened because the driver had a greater concern in maintaining the speed within limits. It was noted that the driver did more lane changes when the average speed was higher, indicating that he had the intention to be faster than the traffic flow.

Considering the driver's profile (Table 6), average speed had a direct correlation with the number of lane changes (0.423), frequency driving on highways (0.387) and years of driving license (0.363). In other words, drivers with more experience had higher average speed and changed their lanes a considerable number of times, indicating a greater confidence in their driving skills.

Quantity of lane change and frequency driving on highways are directly correlated (0.310), indicating that the driver's experience may influence the number of times that he is willing to change lanes. 
Table 6 - Demographic and simulator variables correlation matrix

\begin{tabular}{llcc}
\hline & & Average speed $(\mathbf{k m} / \mathbf{h})$ & Quantity of lane changes \\
\hline Quantity of lane changes & Pearson & $0.423^{* *}$ & \\
& Sig. & $\mathbf{0 . 0 0 1}$ & \\
Years of driving license & Pearson & $0.363^{* *}$ & \\
& Sig. & $\mathbf{0 . 0 0 4}$ & $0.310^{*}$ \\
Frequency driving on highways & Pearson & $0.387^{* *}$ & $\mathbf{0 . 0 1 6}$ \\
& Sig. & $\mathbf{0 . 0 0 2}$ & \\
& & \\
**. The correlation is significant at the 0.1 level (2 ends). & & \\
*. The correlation is significant at the 0.05 (2 ends). &
\end{tabular}

\subsection{ANOVA and multiple comparisons}

The ANOVA test indicated to us the best variables to perform multiple comparisons. In other words, we used it to identify the variables that presented differences in-between the scenarios. In studies with driving simulators, ANOVA is typically followed by multiple comparisons, as discussed by Fisher et al. (2011).

Therefore, we selected the variables with a level of significance inferior to 0.005 (Table 7): easiness to change lanes, easiness to maintain speed, traffic conditions, and psychological comfort. Variables from the simulator records showed no significant statistical differences inbetween scenarios.

Table 7 - Variance analysis results

\begin{tabular}{lcc}
\hline Variable & $\mathbf{Z}$ & Sig. \\
\hline Easiness to change lanes & 6.148 & $\mathbf{0 . 0 0 4}$ \\
Easiness to maintain speed & 13.430 & $\mathbf{0 . 0 0 0}$ \\
Traffic conditions & 7.630 & $\mathbf{0 . 0 0 1}$ \\
Psychological comfort & 8.407 & $\mathbf{0 . 0 0 1}$ \\
Average speed (km/h) & 0.980 & 0.381 \\
Time spent to look at the rearview mirrors (\%) & 2.717 & 0.075 \\
Time spent to look at the speedometer $(\%)$ & 0.944 & 0.395 \\
Quantity of lane changes & 1.586 & 0.214 \\
Standard deviation speed $(\mathrm{km} / \mathrm{h})$ & 0.091 & 0.913 \\
\hline
\end{tabular}

In accordance with the ANOVA results, the Kruskal-Wallis nonparametric test rejected the null hypothesis when considering all three scenarios with the variables easiness to change lanes (sig $=0.006)$, easiness to maintain speed $(\operatorname{sig}<0.001)$, traffic conditions $(\operatorname{sig}=0.001)$ and psychological comfort $(\operatorname{sig}<0.001)$. This indicated that the distribution between these variables and the scenarios studied was not the same.

Table 8 - Level of significance for multiple comparisons by Tukey test

\begin{tabular}{|c|c|c|c|c|c|}
\hline \multirow{2}{*}{\multicolumn{2}{|c|}{ Scenarios }} & \multicolumn{4}{|c|}{ Dependents Variables } \\
\hline & & Easiness to maintain speed & Easiness to change lanes & Traffic conditions & Psychological comfort \\
\hline \multirow{2}{*}{ A } & $\mathrm{C}$ & 0.046 & 0.963 & 0.221 & 0.220 \\
\hline & $E$ & 0.000 & 0.015 & 0.001 & 0.000 \\
\hline \multirow{2}{*}{ C } & $A$ & 0.046 & 0.963 & 0.221 & 0.220 \\
\hline & $\mathrm{E}$ & 0.022 & 0.007 & 0.078 & 0.051 \\
\hline \multirow{2}{*}{$\mathrm{E}$} & A & 0.000 & 0.015 & 0.001 & 0.000 \\
\hline & $\mathrm{C}$ & 0.022 & 0.007 & 0.078 & 0.051 \\
\hline
\end{tabular}


To perform multiple comparisons we used the Tukey test. For the level of significance observed in Table 8, the driver perceived scenario " $A$ " differently than scenario " $E$ " for the variable easiness to change lanes, as well as scenario " $E$ " from scenario " $C$ ". Regarding easiness to maintain speed, all scenarios were perceived differently from each other. For traffic conditions and psychological comfort, the driver perceived differently scenarios with a greater change in densities from each other, between scenario "A" and scenario " $E$ ".

\subsection{Limitations}

There are a few limitations to our study, which may affect the result interpretation. The average speed considered for the traffic flow was the same for the three levels of service under representation, because of lack of data on average speeds for different densities on the highway under study. For future studies, the authors recommend collecting the average speed for different densities. Furthermore, changing the presentation order of the scenarios could avoid any bias in the measured variables.

\section{CONCLUSIONS}

A final comparison of all scenarios highlights that a higher density of vehicles on the highway (LOS E) corresponds to higher levels of stress for the drivers. In traffic flow theory, density is the proportion between flow and speed. The drivers' scores revealed that a larger presence of vehicles caused low maneuverability and lower than desired speeds, making the denser scenario more difficult.

The same observation is valid for quality perception. Low number of vehicles on the highway (LOS A) inspired in drivers the feeling of free flow, with smaller incidence of obstacles and smoother driving. Considering the higher quality of service, driving conditions met the drivers' intentions.

Individually, drivers' performances indicated a degree of concern related to other vehicles at higher densities of traffic flow. This is indicated by the increase in the time that drivers spent looking at rearview mirrors in the highest traffic density scenario (LOS E).

However, in the lowest traffic density scenario, drivers' gaze was more concentrated at the speedometer. This can be interpreted with the speed limit turning into the only true concern for the driver, since no traffic flow was to be followed. A further contribution to this result may derive from the intrinsically limited driver's speed perception caused by the simulator used in this study.

As an additional observation related to speed, it was noted that the longer the time spent looked at the speedometer, the smaller the speed developed by the driver. Experienced drivers evidenced higher average speeds and higher occurrence of traffic maneuvers, attributable to their self-confidence in driving.

When looking at the correlation value between drivers' answers, results indicate that scenarios were distinguished according to their difficulties and qualities. The scenario with the lowest density was classified as lower difficulty and greater quality. The opposite happened with the scenario with the highest density. This difference in perception between scenarios was confirmed on both Tukey and Kruskal-Wallis tests.

Therefore, drivers' experience influenced their driving and different densities were clearly perceived by users. The largest number of vehicles caused reactions in the drivers and limitations that ended up affecting their quality of service perception. 
Thus, our results show potential in measuring the perception of the level of service of drivers using driving simulators. Even with the limitations of the study, the results were interpretable and coherent with the literature.

\subsection{Recommendations}

New experiments could compare the results of the level of perception from driving simulators and more consolidated methods, such as pre-recorded or simulated video displays. We encourage our method to be replicated by other researchers and in other countries, taking into account the improvements suggested on the limitations presented above, to promote better practices related to the analysis of users' perception of quality of service in highways.

\section{ACKNOWLEDGMENTS}

The authors thank the National Council for Scientific and Technological Development (CNPq) for productivity grant scholarships (process 307772/2019-5) and to the São Paulo Research Foundation (FAPESP) for the financial support (grant 2013/25034-5). This study was financed in part by the Coordenação de Aperfeiçoamento de Pessoal de Nível Superior - Brasil (CAPES) - Finance Code 001 and CNPq (process 130424/2015-3 and 142210/2018-8).

\section{REFERENCES}

Antonson, H.; S. Mårdh; M. Wiklund e G. Blomqvist (2009). Effect of surrounding landscape on driving behaviour: A driving simulator study. Journal of Environmental Psychology, pp. 493-502.

Arditi, D.; D. Lee e G. Polat (2007). Fatal accidents in nighttime vs. daytime highway construction work zones. Journal of Safety Research, pp. 399-405.

Castillo, M. A. (2015). Análise da percepção da sinalização vertical rodoviária em ambientes simulados de direção. Um estudo de caso na rodovia BR-116. São Carlos, SP: Thesis (MSc) - São Carlos School of Engineering, University of São Paulo.

Choocharukul, K.; K. C. Sinha e F. L. Mannering (2004). User perceptions and engineering definitions of highway level of service: an exploratory statistical comparison. Transportation Research Part A, 38, pp. 677-689.

De Winter, J. C. F.; P. van Leeuwen e R. Happee (2012). Advantages and Disadvantages of Driving 452 Simulators: A Discussion. Paper presented at the Measuring Behavior, Utrecht, The 453 Netherlands, August 28-31, 2012.

Dowling, R.; A. Skabardonis e V. Alexiadis (2004). Traffic analysis toolbox, volume III: Guidelines for applying traffic microsimulation modeling software. No. FHWA-HRT-04-040. United States. Federal Highway Administration. Office of Operations.

Fang, F. C.; L. Elefteriadou; K. K. Pecheux e M. T. Pietrucha (2003). Using Fuzzy Clustering of User Perception to Define Levels of Service at Signalized Intersections. Journal of Transportation Engineering, 129(6), pp. 657-663.

Fang, F. C. e K. K. Pecheux (2009). Fuzzy Data Mining Approach for Quantifying Signalized Intersection Level of Services Based on User Perceptions. Journal of Transportation Engineering, 135(6), pp. 349-358.

Federal Highway Administration - FHWA (2014). Chapter three: Driving Simulators: Roadway Design and Visualization. In Roadway Human Factors and Behavioral Safety in Europe. USA. Available from:

<http://www.international.fhwa.dot.gov/humanfactors/chapter_three.cfm>. Accessed: 01/26/2016.

Figueira, A. C. e A. P. C. Larocca (2020). Analysis of the factors influencing overtaking in two-lane highways: A driving simulator study. Transportation Research Part F: Traffic Psychology and Behaviour, pp. (69) 38-48.

Field, A. (2009). Discovering Statistics Using SPSS ( $3^{\text {th }}$ ed.). Sage publications, London.

Fisher, D. L.; M. Rizzo; J. K. Caird e J. D. Lee (2011). Driving Simulation for engineering, medicine, and psychology. Taylor and Francis Group. Boca Raton.

Hair Jr., J. F.; R. E. Anderson; R. L. Tatham e W. C. Black (2005). Análise Multivariada de Dados (5a ed.). Bookman, Porto Alegre.

Hall, F.; S. Wakefield e A. Al-Kaisy (2001). Freeway quality of service: what really matters to drivers and passengers? Transportation Research Record: Journal of the Transportation Research Board, № 1776, pp. 17-23.

Horberry, T.; J. Anderson; M. A. Regan; T. J. Triggs e J. Brown (2006). Driver distraction: The effects of concurrent in-vehicle tasks, road environment complexity and age on driving performance. Accident Analysis and Prevention, pp. 185-191.

Hostovsky, C. e F. L. Hall (2003). Freeway quality of service: perceptions from tractor-trailer drivers. Transportation Research Record: Journal of the Transportation Research Board, № 1852, pp. 19-25.

Hostovsky, C.; S. Wakefield e F. Hall (2004). Freeway users' perceptions of quality of service: comparison of three groups. Transportation Research Record: Journal of the Transportation Research Board, № 1883, pp. 150-157.

Jensen, S. U. (2017). Car Drivers' Experienced Level of Service on Freeways. Transportation Research Record: Journal of the Transportation Research Board,№ 2615, pp. 132-139.

Katsikopoulos, K. V. (2011). Advanced guide signs and behavioral decision theory. In: Driving Simulation for engineering, medicine, and psychology, (1-8), pp. 37. 
Larocca, A. P. C.; R. L. Ribeiro; A. C. Figueira; L. C. Lulio e M. A. C. Rangel (2018). Analysis of perception of vertical signaling of highways by drivers in a simulated driving environment. Transportation research part F: traffic psychology and behaviour, 58, pp. 471-487.

Matthews, G.; D. J. Saxby; G. J. Funke; A. M. Emo e P. A. Desmod (2011). Driving in states of fatigue or stress. In: Driving Simulation for engineering, medicine, and psychology, pp. 29 (1-11).

Montgomery, D. C. (2013). Design and Analysis of Experiments. (8 $8^{\text {th }}$ ed). John Wiley \& Sons, Inc.

Nakamura, H.; K. Suzuki e S. Ryu (2000). Analysis of the interrelationship among traffic flow conditions, driving behavior, and degree of driver's satisfaction on rural motorways. Transportation Research Circular E-C018: Proceedings of the Fourth International Symposium on Highway Capacity, pp. 42-52.

Obelheiro, M. R.; H. B. B. Cybis e J. L. D. Ribeiro (2011). Level of Service Method for Brazilian Toll Plazas. Procedia Social and Behavioral Sciences, 16, 120-130.

Oliveira, M. L. (2009). Método para Determinação de Nível de Serviço em Praças de Pedágio. Ph. D. thesis, Universidade Federal do Rio Grande do Sul.

Oehlert, G. W. (2010). A First Course in Design and Analysis of Experiments. University of Minnesota Digital Conservancy. Available from: <http://hdl.handle.net/11299/168002>. Accessed: 01/28/2016.

Paiva, A. P. O. (2015). Percepção dos usuários sobre a qualidade de serviço em rodovias. São Carlos, SP: Thesis (MS) - São Carlos School of Engineering, University of São Paulo.

Paiva, A. P. O. e J. R. Setti (2015). Um Método de Delimitação de Niveis de Serviço com Base na Percepção dos Usuários. In Anais do XXIX Congresso Nacional de Pesquisa em Transporte - ANPET, Ouro Preto. Associação Nacional de Pesquisa e Ensino em Transportes (ANPET).

Papadimitriou, E.; V. Mylona e J. Golias (2010). Perceived level of service, driver, and traffic characteristics: piecewise linear model. Journal of Transportation Engineering, 136 (10), pp. 887-894.

Ramaekers, J. G.; M. R. Moeller; E. L. Theunissen e G. F. Kauert (2011). Validity of three experimental performance tests for predicting risk of cannabis-induced road. In: Driving Simulation for engineering, medicine, and psychology, pp. 45 (1-8).

Rizzo, M.; J. Jermeland e J. Severson (2002). Instrumented vehicles and driving simulators. Gerontechnology, pp. (4) $291-296$.

Santos, M. I.; P. T. M. S. Oliveira; R. L. Ribeiro; A. P. C. Larocca e F. I. Kabbach Junior (2017). Conceito, configuração e aplicação de um simulador de direção no Brasil - Estudo de caso. Revista Transportes, v. 25, nº 2.

Schultheis, M. T.; J. Rebimbas; R. Mourant e S. R. Millis (2007). Examining usability of a virtual reality driving simulator. Assistive Technology, pp. 1-8.

Strayer, D. L.; J. Cooper e F. A. Drews (2011). Profiles in cell phone-induced driver distraction. In: Driving Simulation For Engineering, Medicine, and Psychology, pp. 27 (1-9).

Sullman, M. J. M. e P. H. Baas (2003). Mobile phone use amongst New Zealand drivers. Transportation Research Part F: Traffic Psychology and Behaviour ,7, pp. 95-105.

Torre, A. L. M. (2016). Geometric design consistency analysis of a multilane highway. Thesis (MSc). EESC-USP, Brazil.

TRB (2010). Highway Capacity Manual. Washington D.C.

Underwood, G.; D. Crundall e P. Chapman (2011). Driving simulator validation with hazard perception. Transportation Research Part F: Traffic Psychology and Behaviour, 14(6), pp. 435-446.

Van Driel, C. J. G.; M. Hoedemaeker e B. Van Arem (2006). Impacts of a Congestion Assistant on driving behaviour and acceptance using a driving simulator. Transportation Research Part F: Traffic Psychology and Behaviour, pp. 139-152.

Vieira, F. S. e A. P. C. Larocca (2019). Drivers' speed profile at curves under distraction task, Transportation Research Part F: Traffic Psychology and Behaviour, 44, 12-19.

Washburn, S. S. e D. S. Kirschner (2006). Rural Freeway Level of Service Based on Traveler Perception. Transportation Research Record: Journal of the Transportation Research Board, (№ 1988), pp. 31-37.

Washburn, S. S.; K. Ramlackhan e D. S. McLeod (2004). Quality-of-service perceptions by rural freeway travelers: exploratory analysis. Transportation Research Record: Journal of the Transportation Research Board (№ 1883), pp. 132-139.

Wood, J. e A. Chaparro (2011). Night driving: how low illumination affects driving and the challenges of simulation. In: Driving Simulation for engineering, medicine, and psychology, pp. 28 (1-12). 